\title{
Soluble Tablet Dosage Form
}

National Cancer Institute

\section{Source}

National Cancer Institute. Soluble Tablet Dosage Form. NCI Thesaurus. Code C42985.

A tablet that will dissolve in a liquid solvent to form a solution. 